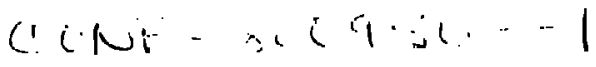

LA-UR -80- 2499

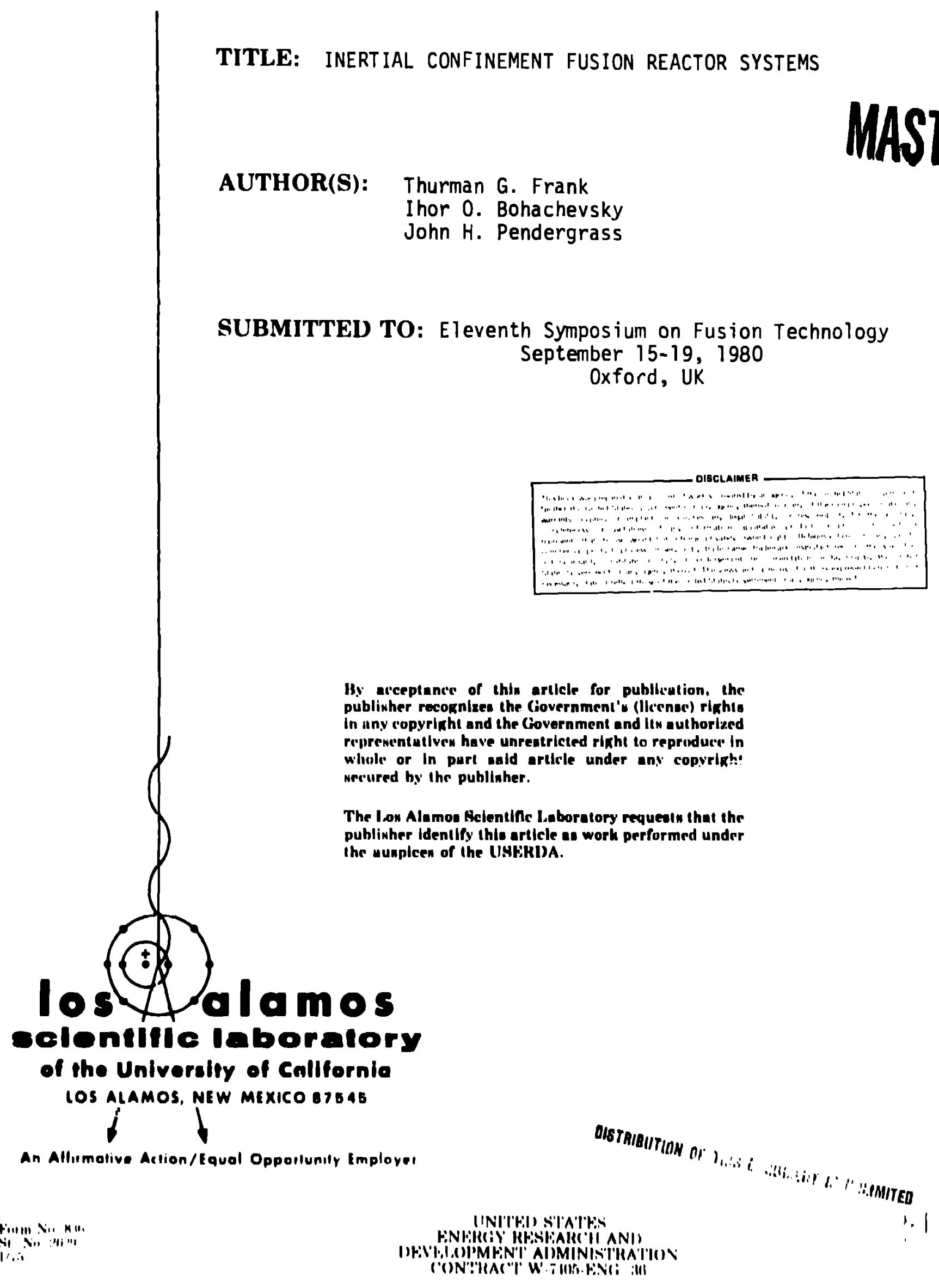




\section{INERTIAL CONFINEMENT FUSION REACTOR SYSTEMS}

T. G. Frank, I. O. Bohachevsky, \& J. H. Pendergrass

Los Alamos Sctentific Laboratory

P.0. Box 1663

Los Alamos, NM 87545

\section{ABSTRACT}

A variety of reactor cavity concepts, drivers, and energy conversion mechanisms are being considered to realize commercial applications of ICF. Presented in this paper are: (1) a review of reactor concepts with estimates of practically achievable pulse repetition rates, (2) a survey of drivers with estimates of the requirements on reactor conditions imposed by beam propagation characteristics, and (3) an assessment of compatible driver-reactor combinations.

\section{INTRODUCTION}

Since about 1969, research has been carried out to develop an alternativis to magentically confined controlled thermonuclear fusion -- that of compressing, heating and confining thermonuclear fuel by inertial forces gererated by the interaction of an intense, pulsed beam energy source ( 0 r $^{\circ}$ driver) with a pellet containing the fuel. The outer region of a fusion pcllet consists of an absorber/ablator material in which energy from a driver source is depostted. This material is blown off creating a recoil impulise which, together with plasnla pressure, heats and compresses the fuel. The'inonuclear ignition occurs at the center of the fuel and propagates radially outward in a time that is short compared to the time required for the pellet to disassemble, resulting in fusion of an appreciable fraclion ol the fuel. Understanding of the fundamental physics of driver-pellet interactions and pellet dynamics is being developed through combined theoretical and experimental investigations.

Inertial confinement fusion (ICF) experimental programs have, thus far, relled principally on the use of short-pulse lasers in pellet implosion experiments, and the construction and use of lasers as research tools will br enphastzed during the next several years to establisn the technical 
feasibility of ICF. Ion beam accelerators are promising alternatives to lasers for driving fusion pellet microexplosions, and programs for development of accelerators with acceptable characteristics are being conducted.

For commercial applications, fusion pellet microexplosions must be repeatedly contained in reactor cavities in a manner that prevents severe damage to reactor components and permits convenient, economic recovery of the energy for conversion to electricity or some other usable forin.

First-generation ICF applications will be based on the tritium-deuterium fut 1 cycle. Reactor cavities must be surrounded by blanket regions containing lithium because tritium for the fuel cycle must be produced in interactions between fusion neutrons and lithlum. Different driver types impose differerit conditions on reactor cavity environments so that facility design for commercial applications must be done for integrated systems.

In the remainder of this paper, reactor concepts now being studied and acceptable driver-reactor combinations are discussed.

\section{REACTOR CONCEPTS}

Fusion pellet microexplosions release energy as $x$ rays, energetic pellal debris, and high-energy neutrons. Reactor components must be protected from excessive damage by $x$ rays and pellet debris, which may cause material loss by eviporation and/or sputtering of exposed surfaces. Several different approaches to protecting cavity walls from $x$ rays and pellet debris are beilı!! studied to assess their feasibility, to identify technology requirements, an:l to determine their acceptablitty for use in combination with various drivers. Sertous damage to reactor structures also results from exposure to high fluences of high-energy neutrons. Provision for moderating neutron inergles to minimize damage to reactor structures are includerl in some reactor concepts.

lnertial-confinement-fusion reactor concepts can be divided into two major categories with regard to acconniodating the photon and debr is encrgy released by pellet microexplosions: (1) concepts in which the energy absorbing surfaces are significantly perturbed by photon and debris energy deposition but are regenerated between pellet microexplosions and (2) concepts in which photon and debris energy are either directly absorbed in solid reactor cavity components or in whtch the debris may be diverted tron the reactor cavity. 
For concepts in the first category, the cavity wall is protected against damage from photons and pellet debris bj either a gas or a protective liquid metal layer. Soft $x$-ray and pellet-debris energy is deposited in the protective material. For some designs, there are restrictions on pellet microexplosion repetition rate due to the time required to restore the cavity after a pellet microexplosion to conditions necessary for pellet injection and beam transport.

In the second category of reactor concepts, photons and pellet debr is are deposited in semi-permanent cavity liners. Near-surface energy deposition can cause evaporation and the pellet debris can cause sputtering of the liner surface. A variant in this category is the use of magnetic fields to divert the ionized pellet debris out the ends of a cylindrical cavicy leaving only the $x$ rays to be accommodated by the cavity wall. There are tradeoffs for minimum damage to material surfaces between relative $x$ ray and pellet debris energy yields and energy spectra. There are generaily no prictical constraints on maximum fellet microexplosion repetition rate for reactor designs in this category.

There have been a large number of ICF reactor concepts proposed during the past decade. Through analytic evaluations of performance, studies of interface conditions in integrated systems, and comparative ersnonic: assessments, the most attractive features of these concepts are being incorporated into a few designs that are compatible with the different oriver. types being developed.

\subsection{Lithium Wetted-Wall Concepts}

The wetted-wall reactor concept was uriginal'y proposed in 1971 [1]. It has been studied and occasionally modifled throughout the past decade. A schematic of this concept is shown in fig. 1. The reactor chamber is spherical and is surrrounded by a blanket region containing liquid lithium and structural components. The cavity wall 1 : formed by a porous metal through which coolant lithium flows $i$ forn a protective layer on the inside surface. The soft $x-$ ay and pellet-cabris enargy is deposited tri the protective lithium layer resulting in partial evaporation and ablation. The 11thlum vapor is subsequently exhausted through a supersonic nozzle at the bottom of the reactor into a cundensor. The protective layer is restored between pellet microexplosions by radtal inflow of lithium from the blarket region. 
The wetted-wall reactor is proposed for use with a laser driver. The vapor density in the cavity must be reduced after a pellet microexplosion to $10^{15}$ to $10^{16}$ atoms $/ \mathrm{cm}^{3}$ for efficient transport of laser beams. The

exhaust nozzle is appropriately sized to evacuate the cavity to this lithium vapor density in $-0.8 \mathrm{~s}$. From this and other considerations the pellet microexplosion repetition rate is constrained to - $1 \mathrm{~Hz}$ or less.

The wetted-wall reactor concept suffers from two potential

disadvantages: (1) a perceived difficulty in monitoring the reestablishment of the protective lithium layer on the cavity interior surface and (2) the limitation on pellet microexplosion repetition frequency. In addition, this concept is not readily adapted to very low cavity vapor density operation. These disadvantages are circumvented by a modified concept [2] shown in $\mathrm{fi}_{3}$. 2 . In the modified concept, liquid lithium is injected tangentially through a circular slit nozzle at the top of the spherical reactor cavity at a ral.: sufficient to remove the $x$-ray and pellet-debris energy as sensible heat of the liquid with only a modest increase in temperature. Positive coverage of the cavity intertor surface is assured by centrifugal forces. Vaporized lithium from pellet microexplosions recondenses on the surface of the injected lithlum stream in time intervals mucin less than required for exhaust through a nozzle. The exhaust nozzle is replace by a simple drain at the bottom of the cavity. The injection nozzle and diverter vanes around veam ports are protected by lithiun films trat are maintained by forced flow through porcus structures.

This reactor concepl could be operated with very low cavity vafor densities by 1 imiting the maximum temperature of the fluid inside the cavity to values corresponding to low vapor pressures. Separate corlant streains of different materials could be used in the reactor cavity and blanket to provide flexibility in choices of vapor pressure and temperature.

A large fraction (60 to $70 \%$ ) of the energy release from pellet microexplosions is deposited directly in the blanket regions of wetted-wall reactors by high-energy neutrons. Blanket coolant is introduced near the cavity wall by struclures concentric with the beam transport tubes. The It thium then flows radially outward through the 1-m-thick blanket. Untform radial flow is achleved by including suffictent impedance to flow in successive structural shells. 
Reference design studies have been done for 150-MJ pellet microexplosions at repetition rates of 1 and $10 \mathrm{~Hz}$, respectively, for the wetted-wall and the modified-wetted-wall concepts. The cavity radii were chosen to be $2 \mathrm{~m}$ from neutron damage considerations. For the modified-wetted-wall concept, a lithium flow rate of $2.4 \mathrm{~m}^{3} / \mathrm{s}$ is required to limit the temperature increase of the cavity coolant to an arbitrary $100 \mathrm{~K}$. This flow rate could be provided by a circular nozzle with a l-cm-wide slit with an injection velocity of $100 \mathrm{~m} / \mathrm{s}$. Analyses of flow profiles through a 2 -m-radius cavity indicate that the lithium thickness increases from $1 \mathrm{~cm}$ at the top of the cavity to $7 \mathrm{~cm}$ at the bottom. Pumping requirements are less than 1 of the electric power produced.

The dominant stresses induced in wetted-wall reactor concepts result from the recoil impulse of the lithium ablated from the interior surface of the cavity wall and from thermal expansion of the lithium blanket due to neutron energy deposition. Stainless steel reactor cavity and blanket structura? walls l-cm thick provide adequate strength to accomnodate the generalen pressures and impulses.

\subsection{High Yield Lithium Injection Fusion Energy (HYLIFE)}

The HYLIFE reactor concept [3] was developed to satisfy several specific. requirements and objectives, includiny: modification of the flux and energy spectra of radiation emitted by pellet microexplosinis with flowing fluids that can be reestablished after each microexplosion, 30-yeal operational lifetime without replacement of damaged or radioactive structure, and mintintzation of development tine.

The reference HYLIFE concept, shown sciematically in fig. 3, consists of an 8-m-high, 10-m-diameter chamber in which a blanket of liquid lithium shields the ste 1 wall fron $x$ rays, pellet debris and high-energy neutrous. The liquid lithlum blanket is composed of a dense hexagonal array 10.5 packing fractionj of 20-cm-dtameter jets. A 300-jct array provides an effective blanket thickness of $1 \mathrm{~m}$ between the pellet microexplosion and the first structural steel wall. The pellet and the driver beams are injected horizontally through specially arranged corridors in the array of jets as shown in fig. 4. 
The energy of the volumetric expansion of lithium, which results from neutron absorption, is primarily deposited in liquid-liquid interactions of colliding jets. The pressure of the lithium vaporized from the inner surface of the blanket by soft $x$ rays and pellet debris exerts an outward force on the blanket, after coalescence of the jets, causing the lithlum to expand outward and collide with the pressure vessel wall; however, the resulting stress is estimated to be acceptable. The large surface area of flowing lithium acts as a condensation pump on which the vaporized lithium is condensed between pellet microexplosions. It is estimated that the jet array will be reestablished and the cavity pressure reduced to that corresponding to the lithium vapor pressure in $-1 \mathrm{~s}$ following a pellet microexplosion. An attractive feature of the HYLIFE concept is that the neutron energy wall loading is reduced by a factor of -20 by the lithium blanket leading to an anticipated chamber lifetime equal to plant lifetime.

Lithium vapor densities at the time of pellet injection and bedill tr ansport can be predetermined by limiting the maximum lithium temperature in the cavity. The nominal maximum lithium temperature for use with laserdrivers is $770 \mathrm{~K}$, corresponding to a lithium vapor density of $-3 \times 10^{15}$ atom $/ \mathrm{cm}^{3}$. It a lithium vapor density $1 \mathrm{imit}$ of $10^{13}$ atom $/ \mathrm{cm}^{3}$ is required, the lithium temperature cannot exceed $-620 \mathrm{~K}$.

The operating characteristics of the reference HYLIFE povier plant includes a pellet yield of $2700 \mathrm{MJ}$ at a repetition rate of $1 \mathrm{~Hz}$. The circulating 1 ithium flow rate is $140 \mathrm{~m}^{3} / \mathrm{s}$ of which 8 : is diverted to a heat exchanger. The temperature increase of the lithtum as it flows through th: reactor chanber is $13 \mathrm{~K}$. The pumping power required for the primary lithium loop is 1.6: of the net electric power produced.

\section{3 lias Filled Reactor Cavities}

The use of a roble gas in reactor cavities to minimize the damaging effects of $x$ rays and pellet debris has been investigated in two regines of gas pressure. Inclusion of a low-pressure gas in reactor cavities has been considered for use with laser drivers, whereas higher presures are appropriate for use with light particle beam drivers.

The most exhaustively studied gas-ftlled reactor concept for use with laser drivers is the SCLASE design [4]. The SOLASE cavity wall and blankel 
structure is made of graphite, and the reactor coolant is circulating lithilum uxide particles. The cavity is filled with $10^{15}$ to $10^{16}$ atoms $/ \mathrm{cm}^{3}$ of xenon or neon. This gas stops the ion debris and attenuates the soft $x$ rays. This energy deposition heats the gas to $1-3 \mathrm{eV}$. The gas then reradiates the absorbed energy in a time interval much longer than the pulse in which it was originally released. Residual heat is removed from the cavity by flowing the gas through the cavity.

The SOLAJE reference cavity design has a $6-m$ radius. The pellet yield is $150 \mathrm{MJ}$ and the repetition rate is $20 \mathrm{~Hz}$. The anticipated lifetime of the structure is $1 \mathrm{yr}$. An advantage of the graphite structure is its low-induced radioactivity permitting limited hands-on maintenance two weeks after shutdown.

Light-ion-beam reactor concepts require a relatively high-density gas $\left(10^{18}\right.$ to $10^{19}$ atom $\left./ \mathrm{cm}^{3}\right)$ in the cavity for beam propagation along ionized channels from the particle source to the pellet. For cavity gas pressure greacer than $10^{13}$ atom $/ \mathrm{cm}^{3}$, all of the pellet debris energy and most of the $x$-ray energy released by the pellet microexplosion are depositell at relatively short ranges resulting in the formation of a hydrodynamic shock. Accommodation of the shock overpressure by the cavity structure leads to optimized cavity designs with relatively large radii. The energy deposited in the cavity gas is reradiated and conducted to the cavity wall in times very long compared to deposition times. Equilibrium gas timperatures are quite high which may pose a pumping problem if the cavity gas is continuously circulated.

Typical operating characteristics for a light-ion-beam drivell reactor include $75-M J$ pellet yields in $3 \times 10^{18}$ atom/ $/ \mathrm{cm}^{3}$ gas with a repetition rate of $10 \mathrm{~Hz}$ and a cavity radius of $4 \mathrm{~m}[5]$.

\subsection{Ablat ive Liners}

For ajplications requiring a very good vacuum in the reactor cavity, the most attractive cavity concept may be a 5 tenl or refractory metal structure with protection from $x$ rays and pellet debris provided by a liner that is allowed to evaporate and ablate at a controlled rate. Protective liners made of carbon have been investigated for this purpose. The cavity radius is made suffictently large to limit surface erosion of the liner so that replacement is not required more often than once per year. 
Ar example of a reactor with a carbon-lined cavity is shown in fig. 5 . The cavity radius required to limit surface erosion to 2 to $3 \mathrm{~cm}$ in one year of operation with $150 \mathrm{MJ}$ microexplosions at $10 \mathrm{~Hz}$ is $10.5 \mathrm{~m}$.

\subsection{Magnetic Deflection}

Since the debris from fusion pellet microexplosions is ionized, it can be defelected away from sensitive reactor components by magnetic fields [6]. The use of magnetic deflection to protect cavity walls and optical components has been investigated. The essential features of such a reactor concept are shown schematically in fig. 6. The reactor cavity is cylindrical, with an impressed steady-state magnetic field produced by a solenoid located concentric with, and exterior to, a lithium blanket region. The ionized pellet debris are diverted by the magnetic fields either through magnetohydrodynamic ducts or to specially designed energy sinks in the ends of the cavity.

Conceptual designs of reactors protected by magnetic deflection are constructed of steel or a refractory metal with additicrial cavity wall protection provided by carbon liners. Designs have been evaluated for use with $150 \mathrm{MJ}$ pellet yields with $10-\mathrm{Hz}$ repetition rates. Cavity radii corresponding to $1-y r$. carbon liner lifetimes are $\sim 2.5 \mathrm{~m}$ for cavities filled with $10^{15}$ atoms $/ \mathrm{cin}^{3}$ of xenon and $7.5 \mathrm{~m}$ for high-vaculm cavities.

3. Driver-Reactor Compdtibility

There are three classes of pulsed beam energy sources now beirig investigated and evaluated for possible use as drivers for ICF; they are lasers, heavy-ion beame, and light-ion beams. Each of these drivers imposes different conditions on reactor interfaces and on cavity conditions suitable for heall injection.

For laser drivers, it is necessary to have optical components (mirrors) in direct line of sigint of the pellet microexplosion. These components are protected from damage from $x$ rays and pellet debris by distance and by a tenuous gas in the bean transport tubes and/or magnetic fields to divert Ionized debris.

Laser beam transport inside reactor cavities can be accomplished through low-density gas; however, there are a great many processes that can result in scattering and defocusing of laser beams, and the upper limit on gas density for efficient transport of focused beams has not been accurately determined. 
A combination of experimental results and theoretical analyses indicate that gas densities less than $\sim 5 \times 10^{15}$ atom $/ \mathrm{cm}^{3}$ do not affect beam propagation significantly.

Driver-reactor interface conditons for heavy-ion beam drivers are currently being assessed. Important considerations will include pressure differences between the reactor cavity and the accelerator, protection of focusing and other magne:s from damage by high-energy neutrons, beam propagation distances, and beam injection configurations. Although severa' approaches to beam transport and focusing inside the reactor cavity are bein? studied, the least uncertainty is associated with ballistic propagation of singly ionized atoms. For particle kinetic energies now being considered, 2 . upper limit on reactor cavity density of $10^{12}$ to $10^{13}$ atoms $/ \mathrm{cm}^{3}$, where two-stream instability is not too serious, is expected to be the prevailing requirement. However, even gas densities in this range are several orders of magnitude higher than $c$ an be tolerated in the accelerator so that vigorous differential pumping at the interface will be required. Beam propagation and focusing in gas densities below $10^{13}$ atom $/ \mathrm{cm}^{3}$ for distances from the focusing magnets of several meters is straightforward; however, space-charge effects may require that the number of beams be large.

Light-ion beams impose entirely different conditions than lasers or heavy-ion beams on driver-reactor interface and cavity conditions. A relatively high-density gas is required in the cavity for beam propagation along ionized channels from the particle source to the pellet. Gas densities which satisfy requirements for beam propagation are in the range $10^{13}$ to $10^{19}$ atoms $/ \mathrm{cm}^{3}$. Preionization along beam paths in the cavity is provided by low-power lasers. Voltage is then applied to the channel electrodes establishing arcs along the preionized paths and creating low-density plasma channels. The ion beam is then magnetically confined to the channel as it propagates to the pellet.

Compatible driver-reactor combinatiuns that have been identified in this discussion are indicated in Table 1 . 
TABLE 1

Compatible Driver-Reactor Combinations for Inertial Conf inement Fusion Driver Type

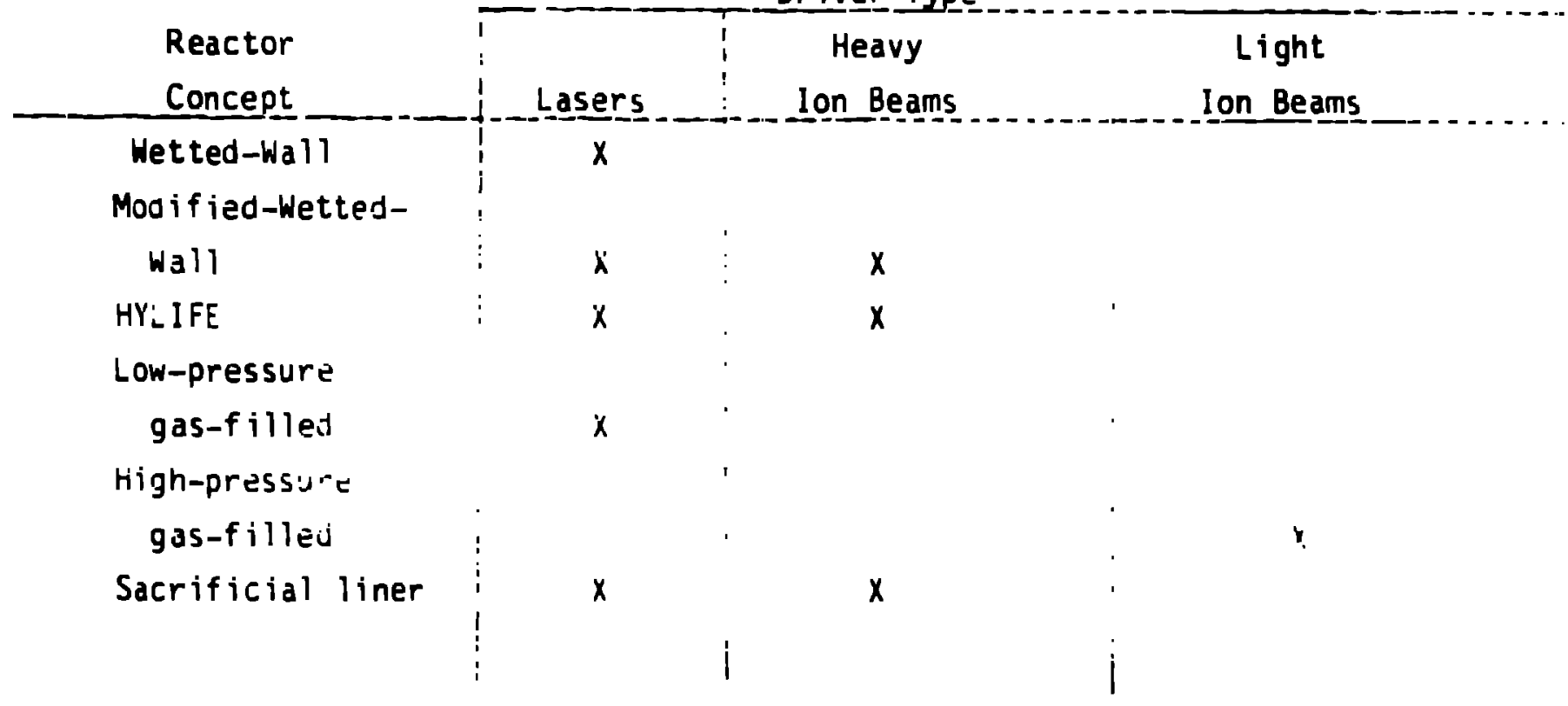

\section{REFERENCES}

[1] Booth, L. A., Los Alamos Scientific Laboratory Report LA-4358-MS, Vol. I (1972).

[2] Pendergrass, J. H. et al., American Nuclear Society Meeting, Las Vegas, NV, 8-13 June 1980. Transactions p. 40.

[3] Meier, H. R. et al., 2nd International Conference on Liquid Metal Technology in Energy Production, Richland, WA, 20-24 April 1980.

[4] Moses, G. A. et al.. 3rd Topical Meeting on the Technology of Controlled Nuclear Fusion, Santa Fe, NM, 9-11 May 1978. Proceedings pp. 448-457.

[5] Cook, D. L.. Sandia Laboratories Report SAND 80-0466C (1980).

[6] Booth, L. A. Proceedings of the IEEE 64, 10, 1460-1482 (1976). 
FIGURE CAPTIONS

Figure 1. Wetted-wall reactor concept.

Figure 2. Modified-wetted-wall reactor concept.

Figure 3. HYLIFE reactor concept.

Figure 4. Beam transport corridor in HYLIFE reactor conceril.

Figure 5. Sacrificial reactor concept.

Figure 6. Magnetic deflection of ion debris in lif reactor. 


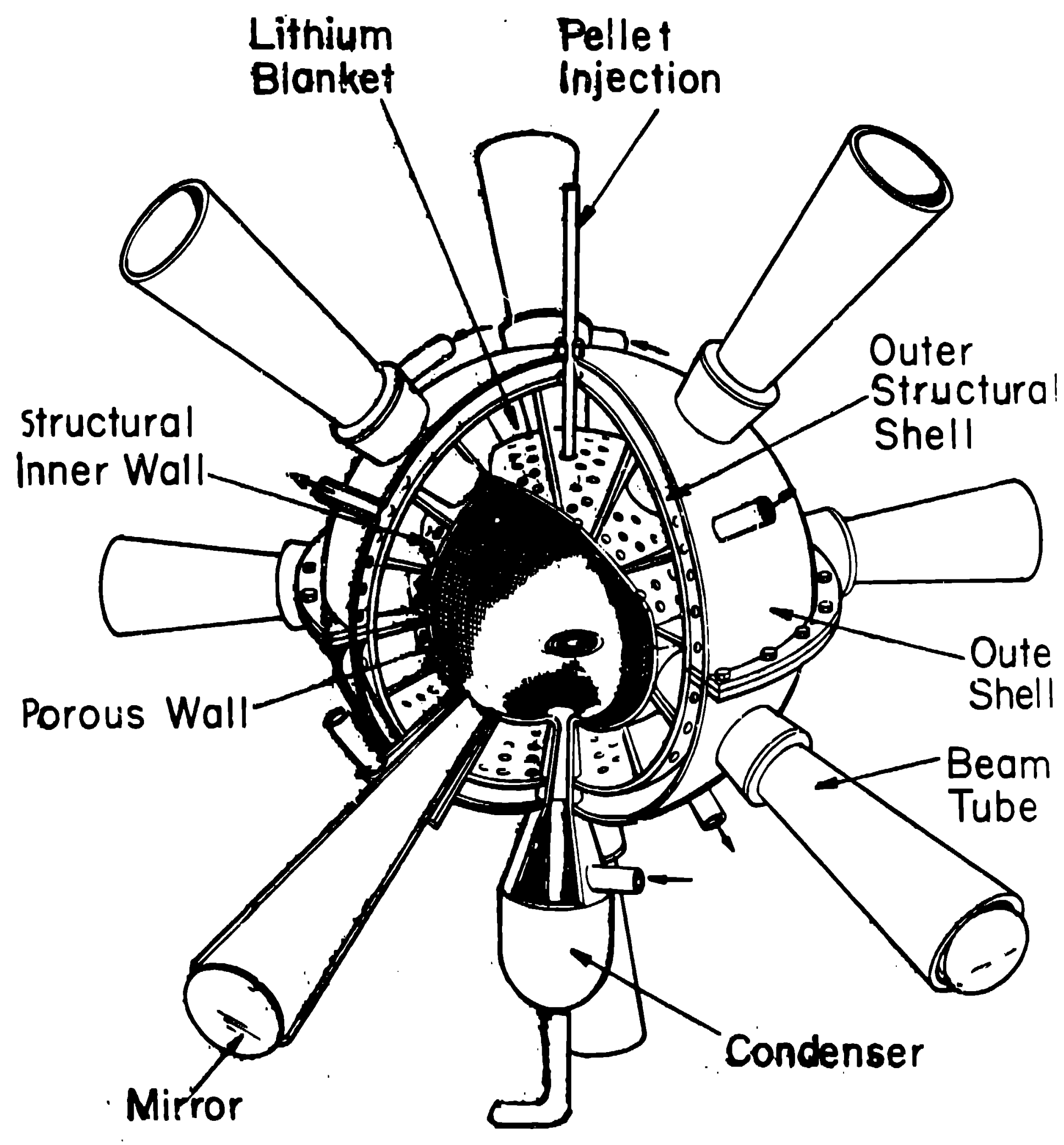

Fig. 1 


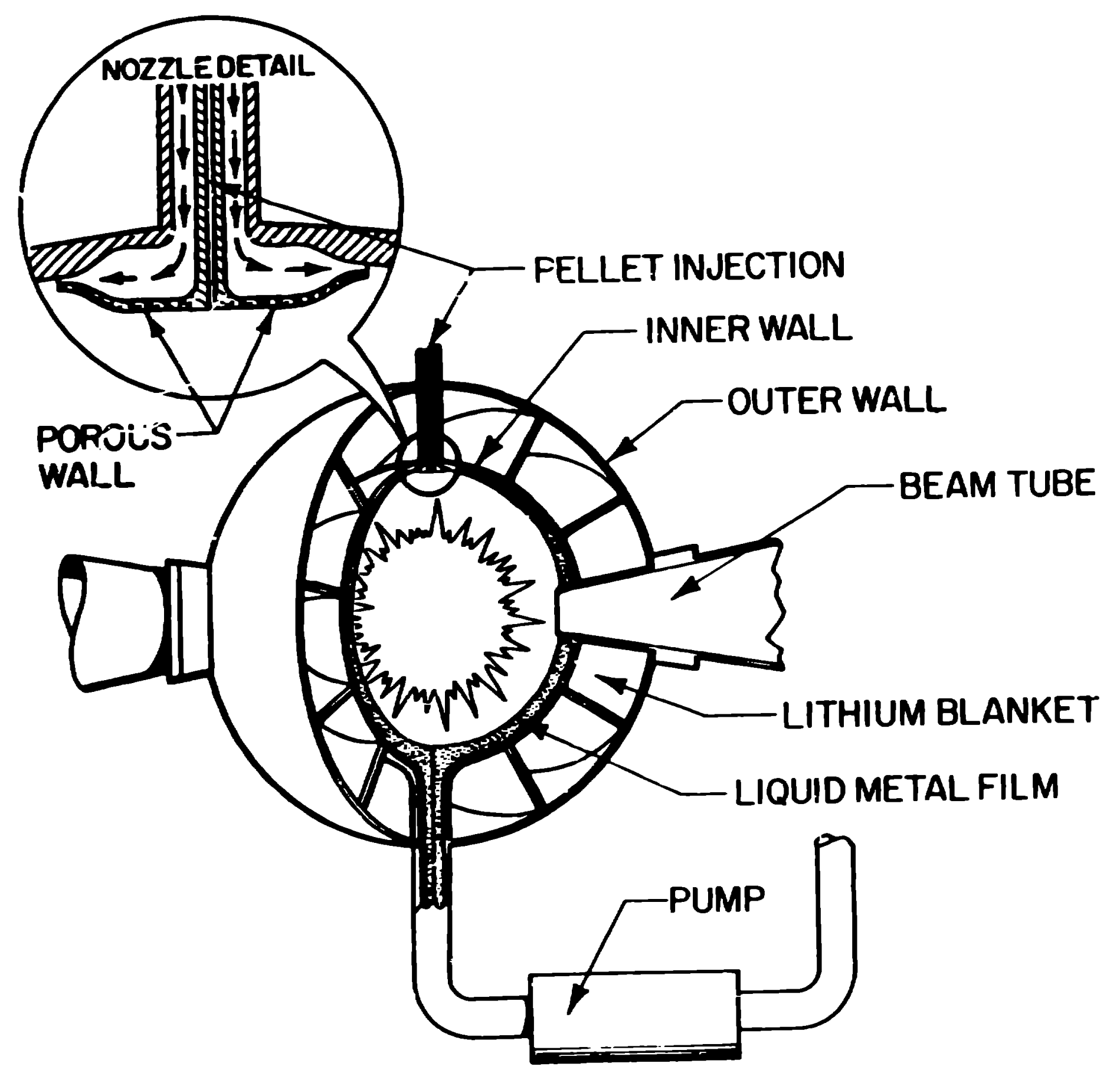

Fig. 2 


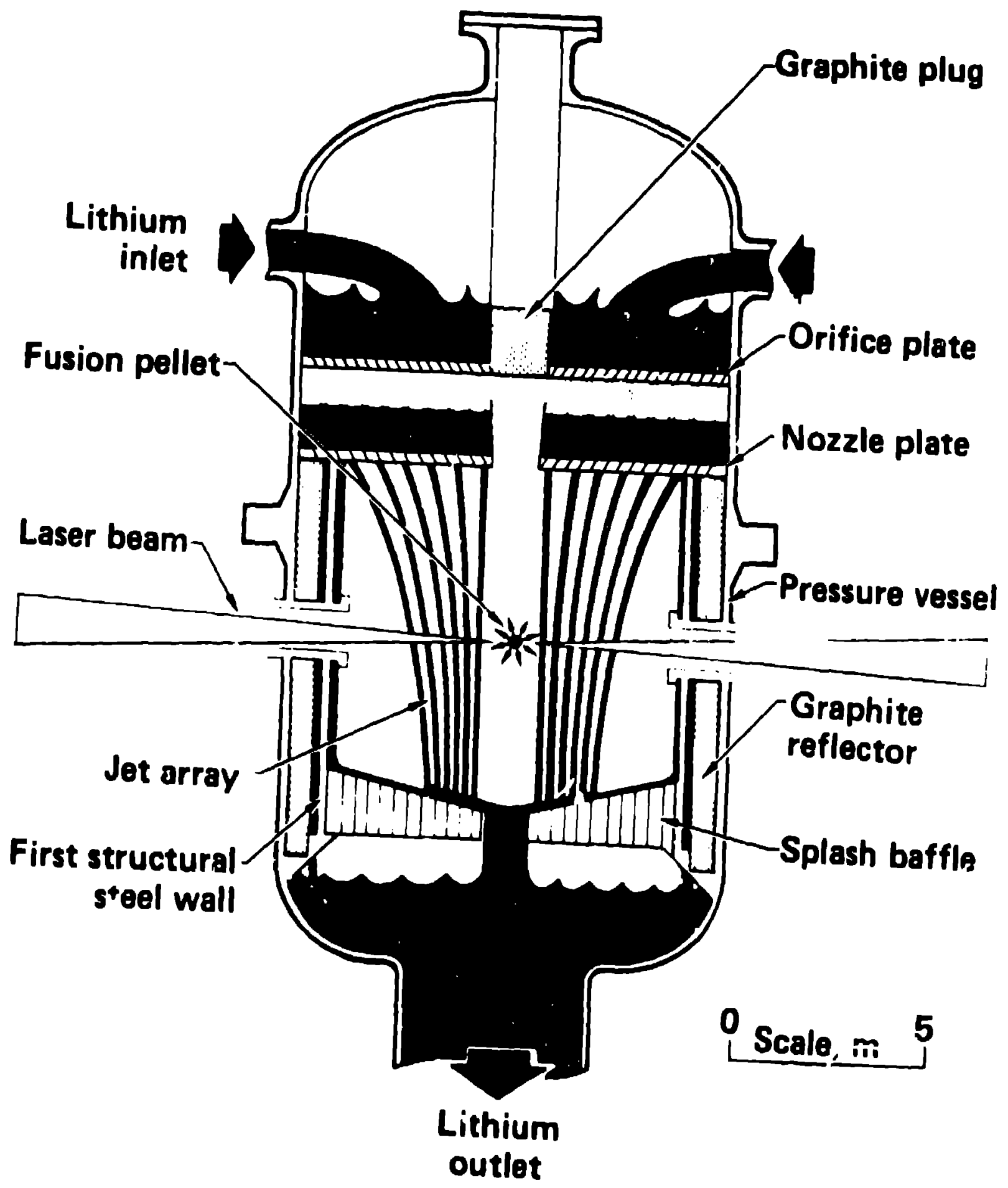

ry. 3 


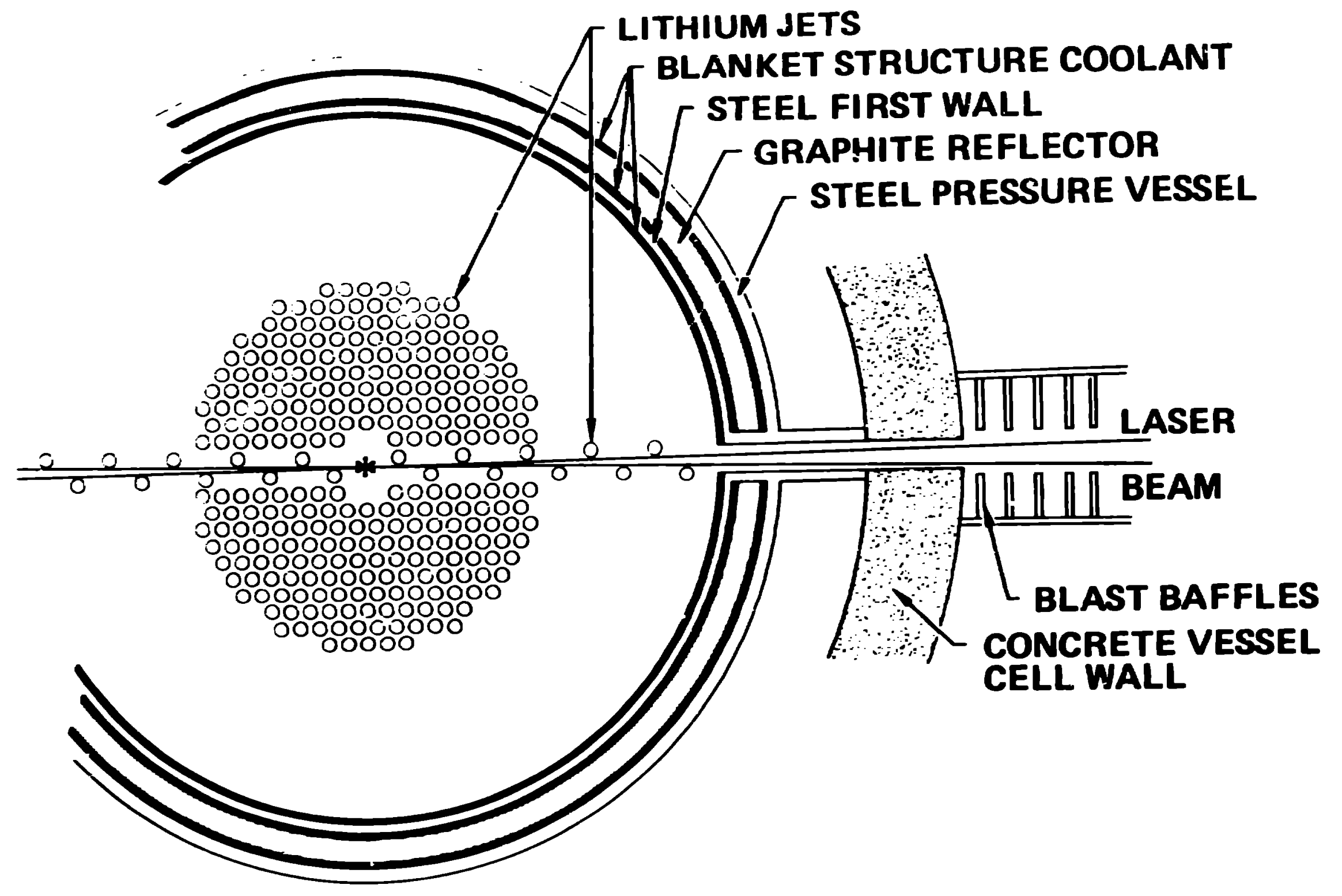

Fig. 4 


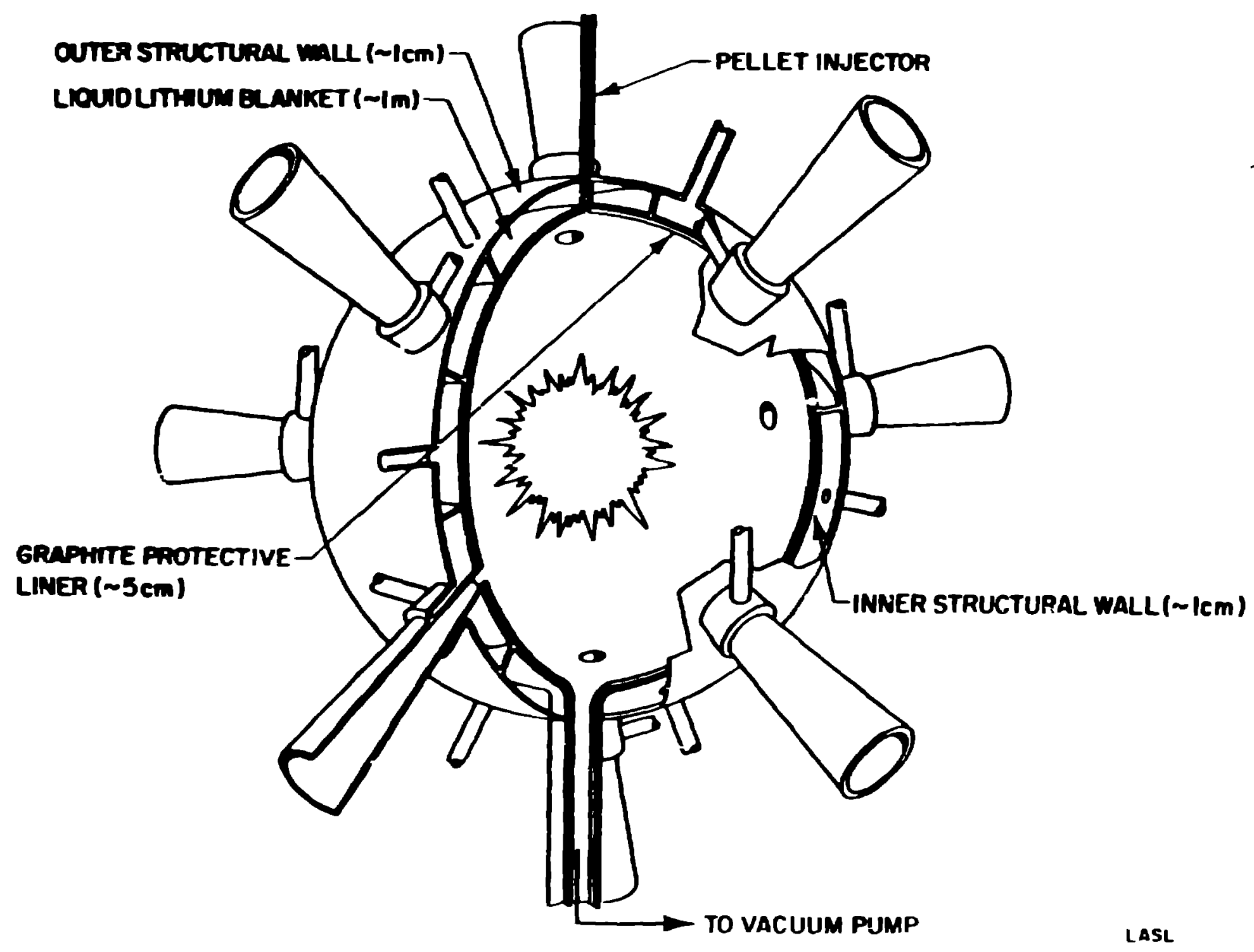

Fig. 5 


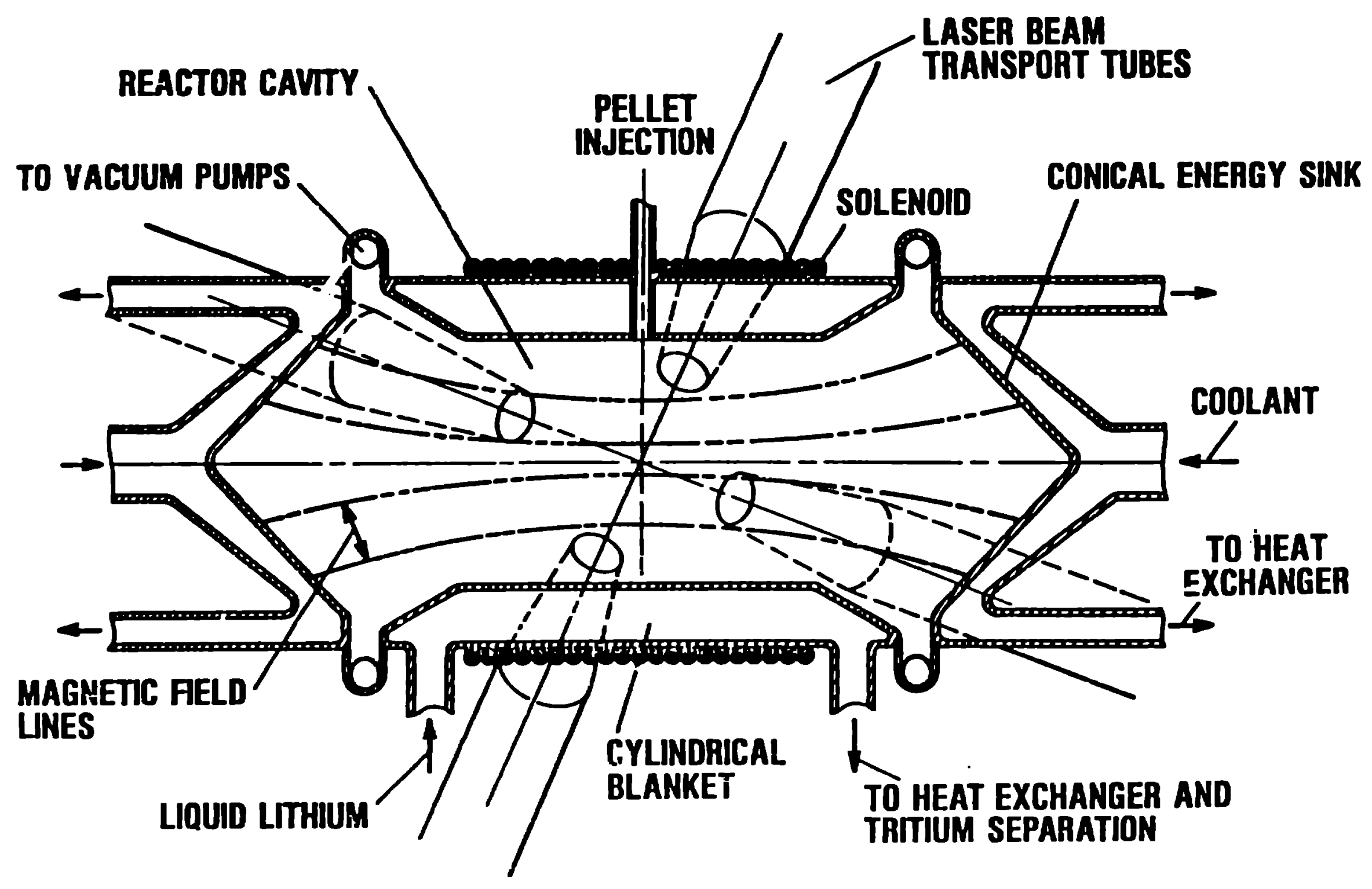

Fig. 6 